\title{
Fructose transport-deficient Staphylococcus aureus reveals important role of epithelial glucose transporters in limiting sugar-driven bacterial growth in airway surface liquid
}

\author{
James P. Garnett · Daniela Braun • Alex J. McCarthy • \\ Matthew R. Farrant • Emma H. Baker • \\ Jodi A. Lindsay $\cdot$ Deborah L. Baines
}

Received: 5 February 2014 / Revised: 11 April 2014 / Accepted: 28 April 2014 / Published online: 9 May 2014

(c) The Author(s) 2014. This article is published with open access at Springerlink.com

\begin{abstract}
Hyperglycaemia as a result of diabetes mellitus or acute illness is associated with increased susceptibility to respiratory infection with Staphylococcus aureus. Hyperglycaemia increases the concentration of glucose in airway surface liquid (ASL) and promotes the growth of $S$. aureus in vitro and in vivo. Whether elevation of other sugars in the blood, such as fructose, also results in increased concentrations in ASL is unknown and whether sugars in ASL are directly utilised by $S$. aureus for growth has not been investigated. We obtained mutant $S$. aureus JE2 strains with transposon disrupted sugar transport genes. NE768(fruA) exhibited restricted growth in $10 \mathrm{mM}$ fructose. In H441 airway epithelial-bacterial co-culture, elevation of basolateral sugar concentration $(5-20 \mathrm{mM})$ increased the apical growth of JE2. However, sugar-induced growth of NE768(fruA) was significantly less when basolateral fructose rather than glucose was elevated. This is the first experimental evidence to show that $S$. aureus directly utilises sugars present in the ASL for growth. Interestingly, JE2 growth was promoted less by glucose than fructose. Net transepithelial flux of D-glucose was lower than D-fructose. However, uptake of D-glucose was higher than D-fructose across both apical and basolateral membranes consistent with the presence of GLUT1/10 in the airway epithelium. Therefore, we propose that the preferential uptake of glucose (compared to fructose) limits its accumulation in ASL. Pre-treatment
\end{abstract}

Electronic supplementary material The online version of this article (doi:10.1007/s00018-014-1635-y) contains supplementary material, which is available to authorized users.

J. P. Garnett · D. Braun · A. J. McCarthy · M. R. Farrant ·

E. H. Baker · J. A. Lindsay · D. L. Baines $(\bowtie)$

Institute for Infection and Immunity, St George's,

University of London, Tooting, London SW17 ORE, UK

e-mail: dbaines@sgul.ac.uk with metformin increased transepithelial resistance and reduced the sugar-dependent growth of $S$. aureus. Thus, epithelial paracellular permeability and glucose transport mechanisms are vital to maintain low glucose concentration in ASL and limit bacterial nutrient sources as a defence against infection.

Keywords Glucose - Glucose transporters (GLUTs) . Hyperglycaemia · Airway epithelium · Staphylococcus aureus $\cdot$ Respiratory infection

\section{Introduction}

Increased risk of Staphylococcus aureus infection in the respiratory tract is associated with hyperglycaemia [1, 2]. Diabetes is a risk factor for nasal colonisation with $S$. aureus [3], increased pathogen load in cystic fibrosis (CF) $[4,5]$ and increased exacerbation frequency in people with chronic obstructive pulmonary disease (COPD) [1, 6].In an intensive care unit, patients with hyperglycaemia had more S. aureus in sputum and this was associated with increased glucose concentration in the thin layer of fluid that lines the airways (airway surface liquid, ASL) [2].

Glucose concentration in human ASL is normally much lower than that of blood at $\sim 0.4 \mathrm{mM},[7-9]$. However, ASL glucose concentrations are elevated in people with respiratory disease including acute viral rhinitis [10], COPD [1] and CF [9]. ASL glucose concentrations are also increased in experimental [11] and diabetic hyperglycaemia [10] and are further increased in people with both respiratory disease and diabetes [5, 9].

We developed an in vitro model of airway glucose homeostasis and showed that, under normal conditions, glucose predominantly diffuses from blood/interstitial fluid 
Table 1 S. aureus parent and mutant strains from the Nebraska sequence-defined transposon library [22]

\begin{tabular}{lllr}
\hline Strain name & Transposon insertion site & Gene description & Accession number \\
\hline JE2 & No mutation & Parent strain & SAUSA 300_247C \\
NE39 $(p t s G)$ & $p t s G$ & Phosphotransferase system, glucose-specific II ABC component & SAUSA 300_0685 \\
NE768 & $f r u A$ & Fructose-specific permease & SAUSA 300_0191 \\
NE172 & $p t s G$ & Phosphotransferase system, glucose-specific II BC component domain protein & SAUSA 300_1315 \\
NE1944 & $c r r$ & Phosphotransferase system, glucose-specific II A component & SAUSA 300_2210 \\
NE1405 & $g l u C$ & Probable glucose uptake protein & S
\end{tabular}

across the respiratory epithelium into the ASL via paracellular pathways, and this is limited by epithelial permeability [8, 12-15]. Uptake via apical and basolateral GLUT transporters also restricts glucose accumulation in ASL [12-16] and rapid metabolism of glucose helps to maintain low intracellular glucose concentrations. This provides a driving force for glucose uptake and limits the transcellular transport of glucose, leading to equilibrated ASL and intracellular glucose concentrations [13, 14]. In this model, increasing the diffusion gradient for glucose across the epithelium (e.g. hyperglycaemia) and increasing paracellular diffusion of glucose via reduced transepithelial resistance $\left(R_{\mathrm{T}}\right)$ (e.g. inflammation) result in elevated ASL glucose concentration $[12,13,17]$.

We have shown that $S$. aureus growth is promoted by glucose in microbial culture [5] and that basolateral hyperglycaemia promotes apical growth of $S$. aureus in airway epithelial co-culture $[12,18]$. S. aureus can also utilise other sugars such as fructose. This sugar has recently received much attention, as it is included as a sweetener in many drinks. In a study of 39 clinical samples, plasma fructose levels were lower than glucose, $46 \pm 25 \mu \mathrm{M}$ compared to $6.19 \pm 2.72 \mathrm{mM}$, but can reach $300 \mu \mathrm{M}$ particularly after ingestion of high-fructose corn syrup [19, 20]. A high-fructose diet has been shown to lead to insulin insensitivity and accelerate the development of type II diabetes in rats [2123]. Elevation of systemic fructose could therefore contribute to the hyperglycaemia-induced growth of $S$. aureus in the airways. It is not known if fructose crosses the lung epithelial cell membrane into ASL where it could provide an additional growth substrate for $S$. aureus. Moreover, there is also no evidence that sugars present in ASL (e.g. glucose or fructose) are directly utilised by $S$. aureus for growth.

We therefore investigated how glucose and fructose modified growth of $S$. aureus carbohydrate transporter mutants in microbial and airway epithelial co-culture. Our data indicate that fructose, in addition to glucose, crosses the airway epithelial barrier and that sugars in ASL are utilised by $S$. aureus to promote growth. In addition, our data indicate that transport of glucose and fructose by airway epithelial cells decreased the transepithelial flux of these sugars. The preferential uptake of glucose over fructose also sheds light on the identity of GLUT transporters involved.

\section{Methods}

Bacterial culture

S. aureus JE2 is a USA300 community-associated methicillin-resistant $S$. aureus used as the parent in construction of the Nebraska sequence-defined transposon insertion library [24]. JE2 and five transposon library mutants with insertions in predicted glucose or fructose sugar transport pathway genes were obtained from the network on antimicrobial resistance in Staphylococcus aureus (NARSA) and are listed in Table 1. For microbial culture, JE2 strains were inoculated into brain heart infusion broth (BHI) and grown overnight at $37{ }^{\circ} \mathrm{C}$. The following day, the culture was diluted to an $\mathrm{OD}_{540}$ of 0.05 using RPMI. Then, $100 \mu \mathrm{l}$ of this adapted culture was added into either $20 \mathrm{ml}$ of glucosefree RPMI, RPMI + $10 \mathrm{mM}$ glucose or RPMI $+10 \mathrm{mM}$ fructose. Cultures were incubated in a shaking water bath at $37{ }^{\circ} \mathrm{C}$ and $80 \mathrm{rpm}$ for $24 \mathrm{~h}$. OD measurements were taken every hour up to $8 \mathrm{~h}$ then again at $24 \mathrm{~h}$. Samples were also removed for Miles and Misra quantification of colony forming units (CFU) on BHI agar. Plates were incubated overnight at $37^{\circ} \mathrm{C}$ and $\mathrm{CFU}$ counted the following day.

For airway epithelial co-culture, a single colony of $S$. aureus strain JE2 or mutant was incubated overnight at $37{ }^{\circ} \mathrm{C}$ in RPMI media containing glucose or fructose. The following day, fresh media was inoculated with $200 \mu \mathrm{l}$ of the overnight culture and grown at $37{ }^{\circ} \mathrm{C}$ to $\log$ phase, $\mathrm{OD}_{540}$ of 0.5 (approximately $2 \times 10^{7} \mathrm{CFU} / \mathrm{ml}$ ).

H441 airway epithelial cell culture and in vitro co-culture model

H441 epithelial cells were grown on permeable membrane supports (Transwells, Corning, MA, USA) at air-liquid interface to form lung epithelial cell layers, as previously described [12]. Monolayers were pre-treated with vehicle or $1 \mathrm{mM}$ metformin (added to the basolateral medium) $18 \mathrm{~h}$ 
prior to apical inoculation with $S$. aureus. Monolayer transepithelial resistance $\left(R_{\mathrm{T}}\right)$ was measured using an epithelial volt ohmmeter (EVOM; World Precision Instruments, UK). For resistance measurements and bacterial co-cultures, the basolateral side of $\mathrm{H} 441$ monolayers was bathed in Krebs salt solution (in $\mathrm{mM}$ ): $\mathrm{NaCl}, 117 ; \mathrm{NaHCO}_{3}, 25 ; \mathrm{KCl}, 4.7$; $\mathrm{MgSO}_{4}, 1.2 ; \mathrm{KH}_{2} \mathrm{PO}_{4}, 1.2 ; \mathrm{CaCl}_{2}, 2.5$ (equilibrated with $5 \% \mathrm{CO}_{2}$ to $\mathrm{pH}$ 7.3-7.4), containing $5 \mathrm{mM}$ glucose or $20 \mathrm{mM}$ glucose or $5 \mathrm{mM}$ glucose $+15 \mathrm{mM}$ fructose.

$S$. aureus cultures were diluted in glucose-free RPMI media and approximately $5 \times 10^{5} \mathrm{CFU}$ of bacteria in $50 \mu \mathrm{l}$ was applied to the apical surface of $\mathrm{H} 441$ monolayers. $\mathrm{H} 441-S$. aureus co-cultures were placed in a $\mathrm{CO}_{2}$ incubator at $37{ }^{\circ} \mathrm{C}$ for $7 \mathrm{~h}$, after which each was homogenised and CFU calculated by plating out serial dilutions.

Paracellular flux and uptake experiments

Paracellular movement of glucose and fructose across H441 monolayers was measured by analysis of radiolabelled $\left[{ }^{14} \mathrm{C}\right]$-L-glucose, $\left[{ }^{14} \mathrm{C}\right]$-D-glucose and $\left[{ }^{14} \mathrm{C}\right]$-D-fructose transepithelial flux. Experiments were initiated by adding $0.5 \mathrm{ml}$ of Krebs salt solution containing $1.0 \mu \mathrm{Ci}$ of radiolabeled sugar plus non-radiolabelled D-glucose $(5 \mathrm{mM})$ and D-fructose $(5 \mathrm{mM})$ to the basolateral side of the transwells and $0.1 \mathrm{ml}$ of sugar-free Krebs solution to the apical side. Apical and basolateral samples were taken after $1 \mathrm{~h}$ and the concentration of radiolabelled glucose was analysed using a scintillation counter. For $\left[{ }^{14} \mathrm{C}\right]$-D-glucose and $\left[{ }^{14} \mathrm{C}\right]$-D-fructose experiments, paracellular flux was calculated by compensating for total monolayer uptake.

Uptake experiments on $\mathrm{H} 441$ monolayers were initiated by replacing the medium with $0.5 \mathrm{ml}$ transport medium containing $1.0 \mu \mathrm{Ci}$ of $\left[{ }^{14} \mathrm{C}\right]$-D-glucose or $\left[{ }^{14} \mathrm{C}\right]$-D-fructose plus $5 \mathrm{mM}$ of non-radiolabelled equivalent $\mathrm{D}$-glucose and D-fructose, to either the basolateral or apical side of the monolayer, followed by incubation at room temperature for $10 \mathrm{~min}$. Preliminary experiments indicated that the uptake was linear between 0 and $10 \mathrm{~min}$ (data not shown). Uptake was terminated by adding $2 \mathrm{ml}$ ice-cold stop solution (15 mM HEPES buffer (pH 7.6); $135 \mathrm{mM}$ choline $\mathrm{Cl} ; 5 \mathrm{mM}$ $\mathrm{KCl} ; 0.8 \mathrm{mM} \mathrm{MgSO}_{4} ; 1.8 \mathrm{mM} \mathrm{CaCl}_{2}$ and $0.2 \mathrm{mM} \mathrm{HgCl}_{2}$ ). The cells were then rinsed twice with $2 \mathrm{ml}$ stop solution and lysed in $0.5 \mathrm{ml}$ of $10 \mathrm{mM}$ Tris- $\mathrm{HCl}(\mathrm{pH} 8.0)$ with $0.2 \%$ SDS. Lysed samples were added to $2 \mathrm{ml}$ scintillation cocktail and radio-active emissions determined using a scintillation counter to quantify glucose and fructose uptake.

\section{Chemicals and reagents}

All chemicals and reagents were obtained from Sigma, Poole, UK unless otherwise stated.
Statistical analysis

Values are reported as mean \pm SEM. Statistical analysis was performed using analysis of variance (ANOVA) and post hoc Bonferroni multiple comparison or Student's $t$ test. $p$ values of $<0.05$ were considered significant.

\section{Results}

Growth of S. aureus mutants in glucose and fructose

The growth curves of parent strain JE2 and the 5 isogenic mutants NE39(ptsG), NE768(fruA), NE1944(crr),

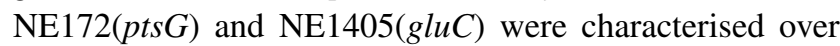
$24 \mathrm{~h}$. To identify genes important for $S$. aureus sugar uptake and growth, the growth of all isogenic mutants was compared to JE2 under three conditions: RPMI medium, RPMI supplemented with $10 \mathrm{mM}$ glucose and RPMI supplemented with $10 \mathrm{mM}$ fructose.

The $\log _{10} \mathrm{OD}_{540}$ indicated that the growth of all six strains in RPMI in the absence of sugar was heavily restricted up to $8 \mathrm{~h}$ (Supplemental Figure 1). There was an observed increase in the $\log _{10} \mathrm{OD}_{540}$ at $24 \mathrm{~h}$ of all strains. Importantly, there was no striking difference in the growth of each isogenic strain compared to JE2 parent strain, indicating that gene disruptions did not impact growth in the absence of sugar.

In the presence of $10 \mathrm{mM}$ glucose, the $\log _{10} \mathrm{OD}_{540}$ for all strains was increased during lag phase and isolates began log phase by $6 \mathrm{~h}$ (Supplemental Figure 1). Strain NE39(ptsG) had the same growth characteristics as the parent strain JE2 but strains NE768(fruA), NE1944(crr), NE172(ptsG) and NE1405 (gluC)were observed to grow more slowly than the parent strain JE2 between 7 and $8 \mathrm{~h}$. After $24 \mathrm{~h}$, all 6 strains reached a similar $\log _{10} \mathrm{OD}_{540}$, which was higher than in RPMI alone (Supplemental Figure 1).

In the presence of $10 \mathrm{mM}$ fructose, the early $\log _{10} \mathrm{OD}_{540}$ for all strains was lower than in glucose. All strains except NE768(fruA) began log phase by $6 \mathrm{~h}$ (Supplemental Figure 1). NE768(fruA) growth was noticeably less than the JE2 parent strain after 7 and $8 \mathrm{~h}(n=2$ each strain). After $24 \mathrm{~h}$, all 6 strains reached a similar $\log _{10} \mathrm{OD}_{540}$, which was higher than in RPMI alone $(0.276 \pm 0.002$ compared to $0.177 \pm 0.005$, respectively, $p<0.0001, n=6$ ).

From these first observational experiments, we then focussed our studies on NE768 (fruA fructose transporter mutant) and the parent strain JE2.

The growth of JE2 was similar in both $10 \mathrm{mM}$ glucose and fructose ( $p>0.05, n=5$, Fig. 1c-f). NE768(fruA) exhibited similar growth to JE2 in $10 \mathrm{mM}$ glucose $(p>0.05$, $n=5$, Fig. 1c, d). However, the growth of NE768(fruA) was significantly inhibited compared to JE2 when grown in 
Fig. 1 Growth of mutant $S$. aureus strains in the presence of glucose and fructose. Growth of S. aureus parent strain (JE2) and mutant strains NE768(fruA), NE172(ptsG), NE1944(crr) measured as OD540 or viable cell assay $(\mathrm{CFU} / \mathrm{ml})$ over $24 \mathrm{~h}$, in glucose-free RPMI $(\mathbf{a}, \mathbf{b})$, RPMI supplemented with $10 \mathrm{mM}$ glucose $(\mathbf{c}, \mathbf{d})$ or RPMI supplemented with $10 \mathrm{mM}$ fructose $(\mathbf{e}, \mathbf{f}), n=5 . * p<0.05$, $* * * * p<0.0001$, compared to JE2
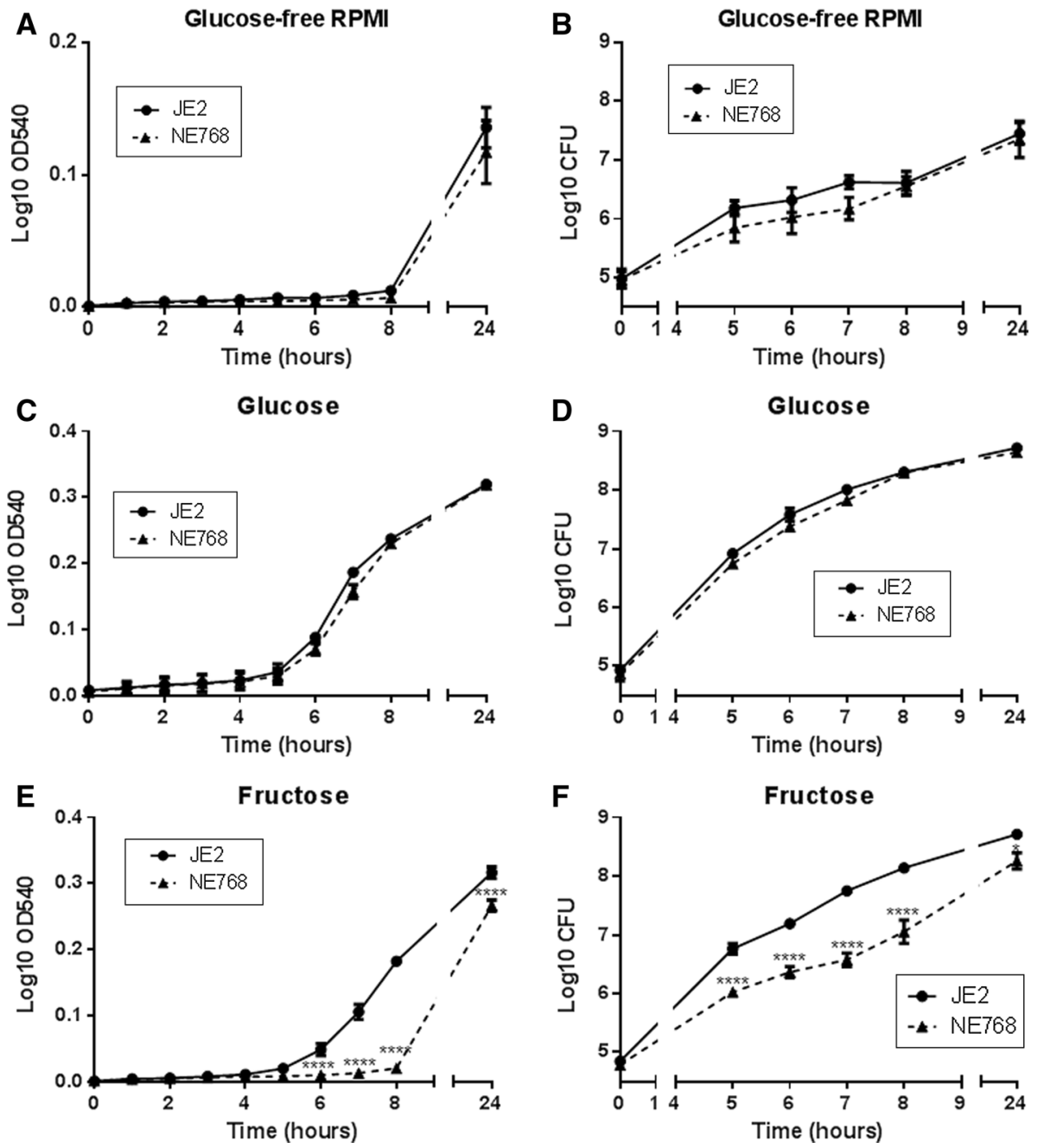

$10 \mathrm{mM}$ fructose, $\log _{10} \mathrm{OD}_{540}$ at $8 \mathrm{~h}$ was $0.014 \pm 0.006$ and $0.181 \pm 0.02$, respectively $(p<0.0001, n=5$, Fig. 1e).Viable counts confirmed $10 \mathrm{mM}$ glucose-induced similar growth of JE2 and NE768(fruA) $(p>0.05, n=5$, Fig. 1d), while viable counts of JE2 in fructose at $8 \mathrm{~h}$ were significantly higher than NE768(fruA) $\left(\log _{10} \mathrm{CFU}\right.$ was $8.14 \pm 0.06$ and $7.05 \pm 0.20$, respectively; $p<0.0001, n=5$, Fig. 1f). These data confirmed that mutation of the fruA gene impacted the ability of strain NE768(fruA) to utilise fructose.

Effect of sugar on transepithelial resistance $\left(R_{\mathrm{T}}\right)$

In our co-culture model, we firstly determined whether changing the glucose or fructose concentration of basolateral solution bathing the H441 airway epithelial cells could adversely affect transepithelial electrical resistance $\left(R_{\mathrm{T}}\right)$, as we previously found that high concentrations of glucose impaired Calu-3 airway epithelial monolayer resistance [15]. Supplementation with 2-20 mM glucose had no significant effect on $R_{\mathrm{T}}$ in $\mathrm{H} 441$ cells grown at air-liquid interface over a time period of $7 \mathrm{~h}$
( $p>0.05, n=5$, Fig. 2). However, H441 $R_{\mathrm{T}}$ was only stable with high concentrations of fructose (10-20 mM). $R_{\mathrm{T}}$ declined significantly when the glucose concentration was reduced to $1 \mathrm{mM}$ ( $p<0.05, n=5)$, or fructose was lowered to $5 \mathrm{mM}(p<0.05, n=5)$. To avoid sugarinduced changes in $R_{\mathrm{T}}$ during H441-S. aureus co-culture experiments, the basolateral solution contained $5 \mathrm{mM}$ glucose(control), which was then supplemented with $15 \mathrm{mM}$ glucose or fructose to measure sugar-induced bacterial growth.

Effect of elevation of basolateral glucose or fructose concentration on the apical growth of JE2 or NE768(fruA) in epithelial-bacterial co-culture

Increasing the basolateral glucose concentration from 5 to $20 \mathrm{mM}$ increased the growth of JE2 and NE768(fruA) on the apical surface of H441 airway epithelial monolayers after $7 \mathrm{~h}(p<0.05, n=5$, Fig. 3a). Addition of $15 \mathrm{mM}$ fructose (plus $5 \mathrm{mM}$ glucose) to the basolateral chamber also increased the apical growth of JE2 $(p<0.05, n=5)$. 


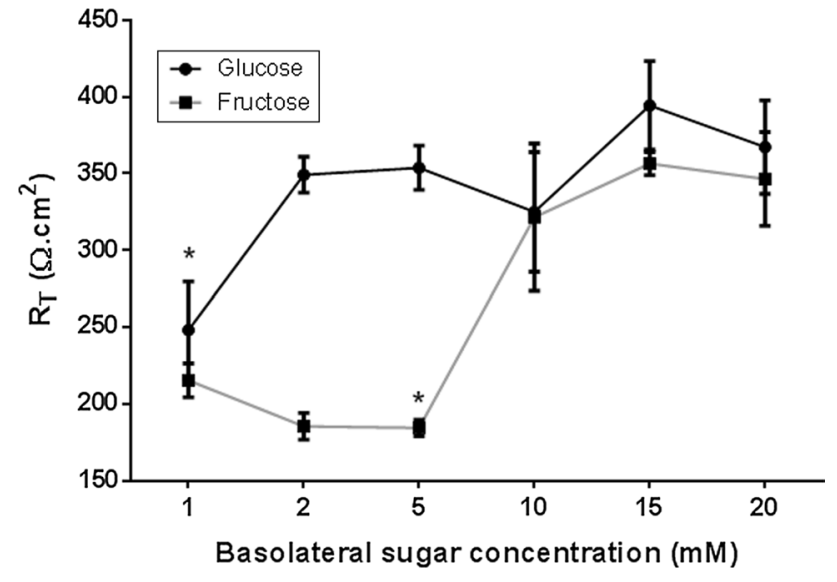

Fig. 2 Sugar-induced changes in transepithelial electrical resistance across airway monolayers. Transepithelial resistance $\left(R_{\mathrm{T}}\right)$ across H441 monolayers after $24 \mathrm{~h}$ incubation with basolateral Krebs salt solution supplemented with 1, 2, 5, 10, 15, $20 \mathrm{mM}$ glucose or fructose, $n=5$. ${ }^{*} p<0.05$ compared to $2 \mathrm{mM}$ glucose, $5 \mathrm{mM}$ glucose, $15 \mathrm{mM}$ glucose, $20 \mathrm{mM}$ glucose, $15 \mathrm{mM}$ fructose and $20 \mathrm{mM}$ fructose

However, the fructose-induced growth of NE768(fruA)was significantly less than that of JE2 $(p<0.01, n=5)$. These data indicate that $S$. aureus directly utilises sugars in the ASL for growth. Analysis of sugar-induced growth in the epithelial-bacterial co-cultures also indicated that fructose induced more growth of JE2 than glucose $(p<0.05, n=5$, Fig. 3a). This was in contrast to JE2 growth in the presence of these two sugars in microbial culture $(p>0.05, n=10$, Fig. 3b).

Fructose and glucose uptake and transepithelial flux across airway epithelial monolayers

A comparison of D-fructose and D-glucose uptake by H441 monolayers revealed that fructose uptake was significantly less than glucose across both apical and basolateral membranes $(p<0.01$ and $p<0.001$, respectively; $n=8$, Fig. 4a, b).

The rate of basolateral-to-apical net transepithelial flux of D-glucose was lower than that of L-glucose (not transported or metabolised) ( $p<0.01, n=4$, Fig. 4c) and lower than that of D-fructose $(p<0.05, n=4)$. Given that net flux of sugars $=$ transepithelial flux - uptake, we calculated transepithelial flux for glucose and fructose. We found that calculated transepithelial flux was similar for glucose and fructose indicating that both similarly cross the epithelium ( $p>0.05, n=4$, Fig. 4d). Moreover, these values were also similar to that of L-glucose which is not transported or metabolised (Fig. 4c, d). Thus, the difference in the rate of apical appearance of D-fructose and D-glucose could be accounted for by the difference in uptake of the two sugars.
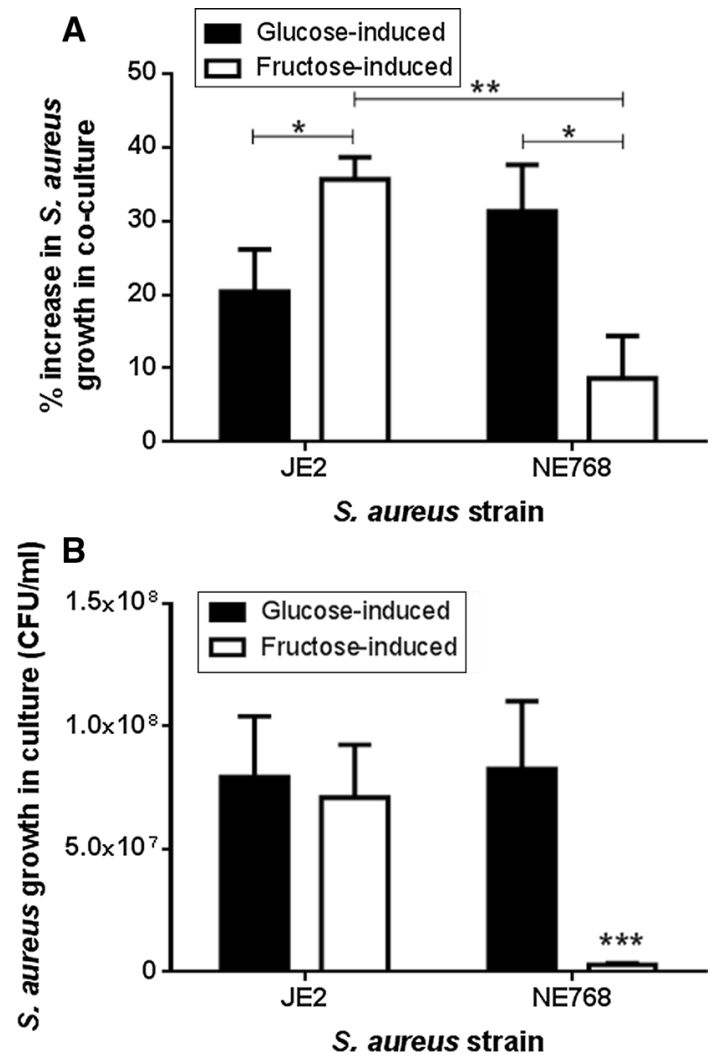

Fig. 3 Apical $S$. aureus growth on airway epithelial monolayers is dependent on basolateral sugar concentration. a H441 airway epithelia-bacteria co-cultures were grown in basolateral Krebs salt solution supplemented with $5 \mathrm{mM}$ glucose (control), $20 \mathrm{mM}$ glucose (glucose-induced growth) or $5 \mathrm{mM}$ glucose $+15 \mathrm{mM}$ fructose (fructoseinduced growth). S. aureus JE2 and NE768(fruA)CFU were measured $7 \mathrm{~h}$ post infection (\% increase compared to growth in the presence of $5 \mathrm{mM}$ basolateral glucose), $n=5$. $* p<0.05$, $* *<0.01$. b Increase in the number of JE2 and NE768(fruA) S. aureus (CFU/ml) in microbial culture over $7 \mathrm{~h}$ in the presence of $10 \mathrm{mM}$ glucose or $10 \mathrm{mM}$ fructose, compared to glucose-free control, $n=10$. ${ }^{*} p<0.05$ compared to all other bars

Effect of metformin on fructose-induced bacterial growth

We previously showed that apical addition of $S$. aureus decreased transepithelial resistance and increased paracellular permeability to glucose [18]. In these experiments, apical addition of $S$. aureus also significantly increased the rate of basolateral-to-apical flux of D-fructose $(p<0.01$, $n=4$, Fig. 5a). Moreover, we previously found that pretreatment of H441 airway epithelial monolayers cells with $1 \mathrm{mM}$ metformin attenuated $S$. aureus-induced changes in the paracellular flux of glucose and reduced glucoseinduced apical $S$. aureus growth. In the current study, metformin pre-treatment of the epithelium also reduced fructose-induced $S$. aureus growth, consistent with paracellular movement of fructose into the ASL providing a stimulus for bacterial growth $(p<0.05, n=4$, Fig. 5b). In 
Fig. 4 Transepithelial flux and uptake of glucose and fructose across airway epithelial monolayers. a Uptake of ${ }^{14} \mathrm{C}$-D-glucose and ${ }^{14} \mathrm{C}$-D-fructose across the apical membrane of $\mathrm{H} 441$ monolayers, $n=8$. b Uptake of ${ }^{14} \mathrm{C}$-D-glucose and ${ }^{14} \mathrm{C}$-D-fructose across the basolateral membrane of H441 monolayers, $n=8$. c Basolateral-to-apical transepithelial flux of D-glucose, D-fructose and L-glucose across H441 monolayers, measured by adding radiolabelled sugar to the basolateral surface and monitoring its appearance of the apical surface over $1 \mathrm{~h}, n=4$. d Calculated basolateral-to-apical transepithelial flux of D-glucose and D-fructose across H441 monolayers, after compensation for epithelial uptake, $n=4 . * p<0.05, * * p<0.01$, $* * * p<0.001$
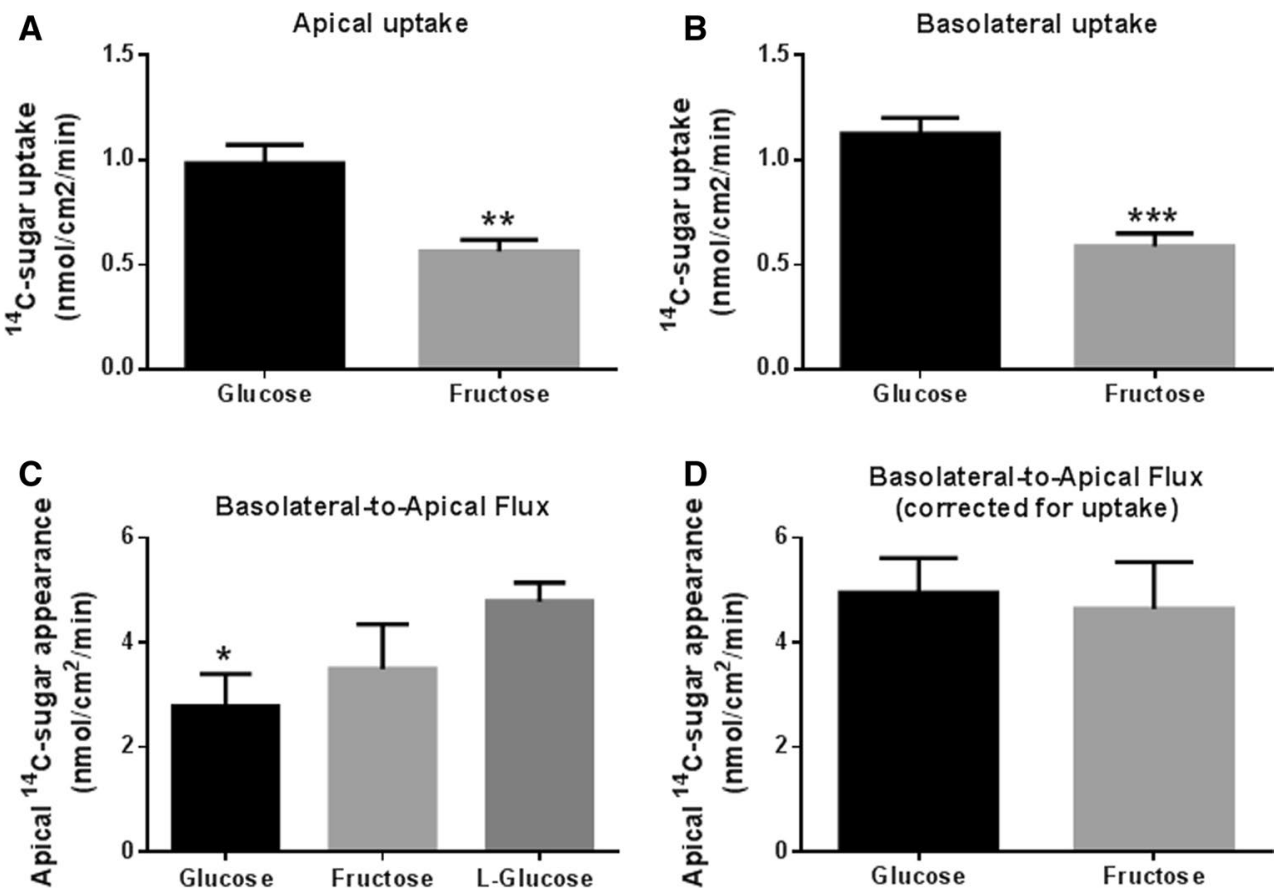

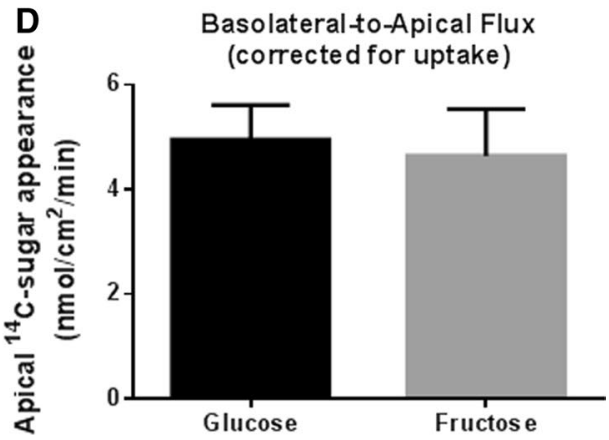

support of this concept, it should be noted that metformin was removed and the epithelial cells were washed prior to the addition of bacteria in co-culture experiments. Furthermore, metformin had no direct effect on $S$. aureus growth in microbial culture ( $n=3$, Supplemental Figure 2).

\section{Discussion}

We previously showed that elevation of basolateral glucose promoted the growth of apical/luminal $S$. aureus in an in vitro model of human airway and that hyperglycaemia promoted the growth of $S$. aureus in mouse airway [18]. We showed that more glucose crossed the epithelial barrier into ASL under these conditions and we proposed that this provided a nutrient source for $S$. aureus [18].

Glucose and other sugars are growth substrates for respiratory pathogens such as S. aureus [25-27]. However, glucose may alter other factors in ASL such as the secretion of antimicrobial proteins [28]. Glucose is also a known trigger for regulatory pathways in $S$. aureus, altering metabolic pathways, expression of virulence factors, and biofilm production [29, 30].

In this study, we wanted to show that sugars present in ASL were taken up and utilised by $S$. aureus for growth. To do this, we used five previously uncharacterized isogenic mutant strains of $S$. aureus JE2. A number of these strains contained disruptions of the putative phosphotransferase system (PTS) which catalyses the transport and phosphorylation of monosaccharides, disaccharides and other sugar derivatives in bacteria. The system is complex and consists of three functional units, IIA, IIB and IIC to which a number of microbial genes contribute. The $\mathrm{crr}$ gene is the structural gene for III ${ }^{\text {Glc }}$, a IIA component of the PTS, and the pts $G$ operon encodes glucose (IICBA) and glucoside-specific enzymes that are sugar permeases, delivering specific sugars to the PTS [31]. In E. coli crr mutants, only $2-3 \%$ in vitro phosphorylation of methyl $\alpha$-glucoside activity was retained [32]. Thus, we expected that disruption of these genes would have a potent effect on glucose uptake and growth in $S$. aureus. Instead, glucose promoted the growth of all mutants and growth of NE1944(crr) and NE172(ptsG) was only inhibited by $\sim 10$ and $20 \%$, respectively, at $8 \mathrm{~h}$. Our findings indicate that either transposon insertion did not lead to complete loss of function of $\mathrm{crr}$ and $p t s G$ genes in $S$. aureus or, more likely, that other pathways provided routes for glucose uptake and metabolism in these mutants [33]. It is possible that the mannose PTS, EIIABCD ${ }^{\mathrm{Man}}$, which has wide substrate specificity and can transport glucose, could provide such a substitute transport system [34-36]. Alternatively, an independent glucose uptake pathway may compensate for the mutations. NE1405 $(g l u C)$ was modified in its glucose uptake protein glc $U$ which may be independent of the PTS pathway. This mutant also grew well in the presence of glucose, presumably because it is compensated by an intact PTS glucose uptake system.

NE768(fruA) carried a mutation in the fruA gene which encodes the putative fructose-specific permease that interacts with the PTS. Fructose promoted the growth of all mutants tested, except NE768(fruA). Growth of this mutant was significantly suppressed for up to $8 \mathrm{~h}$ but reached 

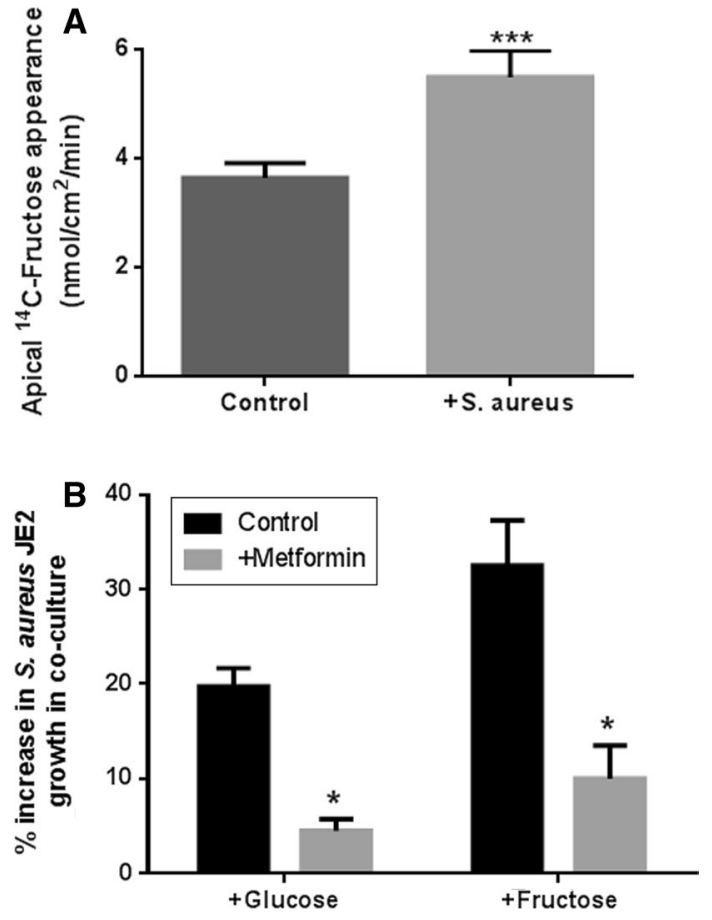

Fig. 5 Metformin reduced the transepithelial flux of fructose and inhibited fructose-induced $S$. aureus JE2 growth across airway epithelial monolayers. a The effect of metformin pre-treatment of $\mathrm{H} 441$ airway epithelial monolayers $(1 \mathrm{mM} ; 18 \mathrm{~h}$ pre-treatment $)$ on the fructose-induced growth of apical $S$. aureus JE2. H441 airway epithelia-bacteria co-cultures were grown in basolateral Krebs salt solution supplemented with $5 \mathrm{mM}$ glucose (control) or $5 \mathrm{mM}$ glucose $+15 \mathrm{mM}$ fructose (fructose-induced growth). S. aureus CFU were measured $7 \mathrm{~h}$ post infection (\% increase compared to growth in the presence of $5 \mathrm{mM}$ basolateral glucose), $n=4$. b Transepithelial flux of fructose across untreated and metformin pre-treated H441 monolayers, measured by adding radiolabelled D-fructose to the basolateral surface and monitoring its appearance of the apical surface, $n=4 .{ }^{*} p<0.05,{ }^{* * *} p<0.001$, compared to control

similar levels to all other mutants at $24 \mathrm{~h}$ in microbial culture. These data indicate that fruA disruption led to an inability to efficiently utilise fructose for growth.

Because the glucose transporter mutations had little impact on bacterial growth, we used NE768(fruA) to identify whether fructose could cross the epithelial barrier and promote apical $S$. aureus growth. We found that elevation of basolateral fructose or glucose concentration promoted the apical growth of JE2 but only glucose effectively promoted the growth of NE768(fruA). These findings indicate that fructose also diffuses across the epithelial barrier into ASL and key to our hypothesis, the growth of $S$. aureus was dependent on the ability of the bacteria to take up and metabolise fructose. This is the first experimental evidence to show that S.aureus directly utilises sugars present in the ASL.

We noted that apical growth of JE2 was greater when the concentration of basolateral fructose, rather than glucose, was raised in epithelial-bacterial co-culture. This was in contrast to bacterial culture, where there was no difference in fructose- or glucose-induced growth over a similar time period. We previously showed that glucose diffuses across the airway epithelium into ASL, but its concentration is kept low by epithelial glucose transport and metabolism [12, 13, 16, 37]. Our data show that both glucose and fructose similarly diffused from the basolateral compartment into ASL and that paracellular flux was increased by the presence of bacteria [18]. However, the basolateral and apical uptake of fructose by $\mathrm{H} 441$ cells was significantly lower than that of glucose. Since pharmacological inhibition of GLUT-mediated glucose uptake with phloretin led to increased apical accumulation of glucose [13], we propose that, in this experimental model, reduced fructose uptake resulted in increased accumulation of fructose in ASL providing more availability of nutrients for wild-type JE2 growth.

These data and our finding that the $R_{\mathrm{T}}$ of epithelial monolayers decreased in fructose concentrations lower than $10 \mathrm{mM}$, but only in glucose concentrations lower than $2 \mathrm{mM}$, also shed important light on the potential identity of glucose transporters (GLUTs) that regulate glucose uptake and ASL glucose concentration. We identified glucose transporters GLUT2 and GLUT10 in H441 cells [15]. GLUT1 and GLUT10 were identified in primary human bronchiolar epithelial cells (HBE) [14]. GLUT2 transports glucose and fructose with similar low affinity $\left(K_{\mathrm{m}} \sim 15 \mathrm{mM}\right)$ [38, 39]. GLUT1 and GLUT10 transport glucose with higher affinity $\left(K_{\mathrm{m}} \sim 5.0\right.$ and $0.3 \mathrm{mM}$, respectively), but do not transport fructose [40, 41]. Thus, the increased uptake of glucose compared to fructose points towards the involvement of GLUT1 and/or GLUT10 in this process. In our previous studies, we were unable to identify GLUT1 in H441 cells, but GLUT10 protein expression correlated with increased glucose uptake in response to proinflammatory agents [12]. As GLUT10 is localised to the mitochondria in vascular smooth muscle cells $[42,43]$ and mutations of the SLC2A10 gene are associated with arterial tortuosity syndrome [44], more work is now required to elucidate this potentially distinct role of GLUT10 in the airway.

Treatment of H441 cells with metformin inhibited both glucose-and fructose-induced growth of JE2 and was associated with restoration of airway epithelial $R_{\mathrm{T}}$ consistent with our previous findings [18]. Both glucose and fructose are similar sized, non-charged, hexose molecules. Thus, these data further support our model where by metformin reduced paracellular flux of sugars limiting their accumulation in ASL and availability as nutrients for $S$. aureus growth [13].

In conclusion, we characterised a number of $S$. aureus carbohydrate transporter mutants and identified 
NE768(fruA) (a fruA mutant) with a reduced ability to utilise fructose as a growth substrate. Use of this mutant in epithelial-bacterial co-culture showed that $S$. aureus directly utilised sugars present in ASL for growth. Both fructose and glucose diffuse across the airway epithelium into ASL. However, epithelial uptake of fructose is less than that of glucose. We propose this is because key transporters present in the airway epithelium preferentially transport glucose (e.g. GLUT1/10). This decreases the diffusion gradient for paracellular movement of glucose compared to fructose and more effectively removes glucose from ASL. Given that blood glucose concentrations are much higher than fructose in vivo, glucose rather than fructose is more important as a bacterial nutrient source and preferential transport mechanisms would therefore be physiologically relevant. Consistent with our previous study, metformin significantly raised $R_{\mathrm{T}}$ and reduced the sugar-dependent growth of $S$. aureus. Thus, epithelial paracellular permeability and glucose transport mechanisms are vital to maintaining low glucose concentration in ASL and limiting bacterial nutrient sources as a defence against infection.

Acknowledgments This work was supported by the WellcomeTrust (Grant No: 088304/Z/09/Z), the Medical Research Council (Grant No: MR/K012770/1) and an Enterprise grant from St. George's University of London.

Open Access This article is distributed under the terms of the Creative Commons Attribution License which permits any use, distribution, and reproduction in any medium, provided the original author(s) and the source are credited.

\section{References}

1. Baker EH, Janaway CH, Philips BJ, Brennan AL, Baines DL, Wood DM, Jones PW (2006) Hyperglycaemia is associated with poor outcomes in patients admitted to hospital with acute exacerbations of chronic obstructive pulmonary disease. Thorax 61:284-289

2. Philips BJ, Redman J, Brennan A, Wood D, Holliman R, Baines D, Baker EH (2005) Glucose in bronchial aspirates increases the risk of respiratory MRSA in intubated patients. Thorax 60:761-764

3. Tamer A, Karabay O, Ekerbicer H (2006) Staphylococcus aureus nasal carriage and associated factors in type 2 diabetic patients. Jpn J Infect Dis 59:10-14

4. Merlo CA, Boyle MP, Diener-West M, Marshall BC, Goss CH, Lechtzin N (2007) Incidence and risk factors for multiple antibiotic-resistant Pseudomonas aeruginosa in cystic fibrosis. Chest 132:562-568

5. Brennan AL, Gyi KM, Wood DM, Johnson J, Holliman R, Baines DL, Philips BJ, Geddes DM, Hodson ME, Baker EH (2007) Airway glucose concentrations and effect on growth of respiratory pathogens in cystic fibrosis. J Cyst Fibros 6:101-109

6. Kupeli E, Ulubay G, Ulasli SS, Sahin T, Erayman Z, Gursoy A (2010) Metabolic syndrome is associated with increased risk of acute exacerbation of COPD: a preliminary study. Endocrine $38: 76-82$
7. Barker PM, Boyd CA, Ramsden CA, Strang LB, Walters DV (1989) Pulmonary glucose transport in the fetal sheep. J Physiol 409:15-27

8. Saumon G, Martet G (1996) Effect of changes in paracellular permeability on airspace liquid clearance: role of glucose transport. Am J Physiol 270:L191-L198

9. Baker EH, Clark N, Brennan AL, Fisher DA, Gyi KM, Hodson ME, Philips BJ, Baines DL, Wood DM (2007) Hyperglycemia and cystic fibrosis alter respiratory fluid glucose concentrations estimated by breath condensate analysis. J Appl Physiol 102:1969-1975

10. Philips BJ, Meguer JX, Redman J, Baker EH (2003) Factors determining the appearance of glucose in upper and lower respiratory tract secretions. Intensive Care Med 29:2204-2210

11. Wood DM, Brennan AL, Philips BJ, Baker EH (2004) Effect of hyperglycaemia on glucose concentration of human nasal secretions. Clin Sci (Lond) 106:527-533

12. Garnett JP, Nguyen TT, Moffatt JD, Pelham ER, Kalsi KK, Baker EH, Baines DL (2012) Proinflammatory mediators disrupt glucose homeostasis in airway surface liquid. J Immunol 189:373-380

13. Kalsi KK, Baker EH, Fraser O, Chung YL, Mace OJ, Tarelli E, Philips BJ, Baines DL (2009) Glucose homeostasis across human airway epithelial cell monolayers: role of diffusion, transport and metabolism. Pflugers Arch 457:1061-1070

14. Pezzulo AA, Gutierrez J, Duschner KS, McConnell KS, Taft PJ, Ernst SE, Yahr TL, Rahmouni K, Klesney-Tait J, Stoltz DA, Zabner J (2011) Glucose depletion in the airway surface liquid is essential for sterility of the airways. PLoS One 6:e16166

15. Garnett JP, Gray MA, Tarran R, Brodlie M, Ward C, Baker EH, Baines DL (2013) Elevated paracellular glucose flux across cystic fibrosis airway epithelial monolayers is an important factor for Pseudomonas aeruginosa growth. PLoS One 8:e76283

16. Kalsi KK, Baker EH, Medina RA, Rice S, Wood DM, Ratoff JC, Philips BJ, Baines DL (2008) Apical and basolateral localisation of GLUT2 transporters in human lung epithelial cells. Pflugers Arch 456:991-1003

17. Myerburg MM, King JD Jr, Oyster NM, Fitch AC, Magill A, Baty CJ, Watkins SC, Kolls JK, Pilewski JM, Hallows KR (2010) AMPK agonists ameliorate sodium and fluid transport and inflammation in cystic fibrosis airway epithelial cells. Am J Respir Cell Mol Biol 42:676-684

18. Garnett JP, Baker EH, Naik S, Lindsay JA, Knight GM, Gill S, Tregoning JS, Baines DL (2013) Metformin reduces airway glucose permeability and hyperglycaemia-induced Staphylococcus aureus load independently of effects on blood glucose. Thorax 68:835-845

19. Le MT, Frye RF, Rivard CJ, Cheng J, McFann KK, Segal MS, Johnson RJ, Johnson JA (2012) Effects of high-fructose corn syrup and sucrose on the pharmacokinetics of fructose and acute metabolic and hemodynamic responses in healthy subjects. Metabolism 61:641-651

20. Wahjudi PN, Patterson ME, Lim S, Yee JK, Mao CS, Lee WN (2010) Measurement of glucose and fructose in clinical samples using gas chromatography/mass spectrometry. Clin Biochem 43:198-207

21. Sheludiakova A, Rooney K, Boakes RA (2012) Metabolic and behavioural effects of sucrose and fructose/glucose drinks in the rat. Eur J Nutr 51:445-454

22. Stanhope KL, Havel PJ (2010) Fructose consumption: recent results and their potential implications. Ann N Y Acad Sci 1190:15-24

23. Cummings BP, Stanhope KL, Graham JL, Evans JL, Baskin DG, Griffen SC, Havel PJ (2010) Dietary fructose accelerates the development of diabetes in UCD-T2DM rats: amelioration by the antioxidant, alpha-lipoic acid. Am J Physiol Regul Integr Comp Physiol 298:R1343-R1350 
24. Fey PD, Endres JL, Yajjala VK, Widhelm TJ, Boissy RJ, Bose JL, Bayles KW (2013) A genetic resource for rapid and comprehensive phenotype screening of nonessential Staphylococcus aureus genes. MBio 4:e00537-e00612

25. Brennan A, Baines D, Woollhead A, Lindsay J, Hayes M, Philips B, Baker E (2006) Development of an in vitro model to investigate the effect of glucose on the interaction between respiratory epithelia and bacterial pathogens. Thorax 61:101

26. Donenko FV, Gruber IM, Semenova IB, Priyatkin RG, Ziganshin RH, Zaryadyeva EA, Ignatova OM, Kurbatova EA, Kiselevsky MV, Efferth T (2011) Growth-dependent release of carbohydrate metabolism-related and antioxidant enzymes from Staphylococcus aureus strain 6 as determined by proteomic analysis. Exp Ther Med 2:1199-1204

27. Strasters KC, Winkler KC (1963) Carbohydrate metabolism of Staphylococcus aureus. J Gen Microbiol 33:213-229

28. Lee RJ, Kofonow JM, Rosen PL, Siebert AP, Chen B, Doghramji L, Xiong G, Adappa ND, Palmer JN, Kennedy DW, Kreindler JL, Margolskee RF, Cohen NA (2014) Bitter and sweet taste receptors regulate human upper respiratory innate immunity. J Clin Invest 124:1393-1405

29. Seidl K, Goerke C, Wolz C, Mack D, Berger-Bachi B, Bischoff M (2008) Staphylococcus aureus CcpA affects biofilm formation. Infect Immun 76:2044-2050

30. Seidl K, Muller S, Francois P, Kriebitzsch C, Schrenzel J, Engelmann S, Bischoff M, Berger-Bachi B (2009) Effect of a glucose impulse on the CcpA regulon in Staphylococcus aureus. BMC Microbiol 9:95

31. Knezevic I, Bachem S, Sickmann A, Meyer HE, Stulke J, Hengstenberg W (2000) Regulation of the glucose-specific phosphotransferase system (PTS) of Staphylococcus carnosus by the antiterminator protein GlcT. Microbiology 146(Pt 9):2333-2342

32. Meadow ND, Saffen DW, Dottin RP, Roseman S (1982) Molecular cloning of the crr gene and evidence that it is the structural gene for IIIGlc, a phosphocarrier protein of the bacterial phosphotransferase system. Proc Natl Acad Sci USA 79:2528-2532

33. Siebold C, Flukiger K, Beutler R, Erni B (2001) Carbohydrate transporters of the bacterial phosphoenolpyruvate: sugar phosphotransferase system (PTS). FEBS Lett 504:104-111

34. Curtis SJ, Epstein W (1975) Phosphorylation of D-glucose in Escherichia coli mutants defective in glucose phosphotransferase, mannose phosphotransferase, and glucokinase. J Bacteriol 122:1189-1199

35. Kornberg HL, Jones-Mortimer MC (1975) PtsX: a gene involved in the uptake of glucose and fructose by Escherichia coli. FEBS Lett 51:1-4

36. Plumbridge $\mathbf{J}$ (2000) A mutation which affects both the specificity of PtsG sugar transport and the regulation of ptsG expression by Mlc in Escherichia coli. Microbiology 146(Pt 10):2655-2663

37. Garnett JP, Baker EH, Baines DL (2012) Sweet talk-insights into the nature and importance of glucose transport in lung epithelium. Eur Respir J 40:1269-1276

38. Colville CA, Seatter MJ, Jess TJ, Gould GW, Thomas HM (1993) Kinetic analysis of the liver-type (GLUT2) and brain-type (GLUT3) glucose transporters in Xenopus oocytes: substrate specificities and effects of transport inhibitors. Biochem J 290(Pt 3):701-706

39. Cheeseman CI (1993) GLUT2 is the transporter for fructose across the rat intestinal basolateral membrane. Gastroenterology 105:1050-1056

40. Dawson PA, Mychaleckyj JC, Fossey SC, Mihic SJ, Craddock AL, Bowden DW (2001) Sequence and functional analysis of GLUT10: a glucose transporter in the Type 2 diabeteslinked region of chromosome 20q12-13.1. Mol Genet Metab 74:186-199

41. Manolescu AR, Witkowska K, Kinnaird A, Cessford T, Cheeseman C (2007) Facilitated hexose transporters: new perspectives on form and function. Physiology (Bethesda) 22:234-240

42. Lee YC, Huang HY, Chang CJ, Cheng CH, Chen YT (2010) Mitochondrial GLUT10 facilitates dehydroascorbic acid import and protects cells against oxidative stress: mechanistic insight into arterial tortuosity syndrome. Hum Mol Genet 19:3721-3733

43. Pyla R, Poulose N, Jun JY, Segar L (2013) Expression of conventional and novel glucose transporters, GLUT1, -9, -10, and -12, in vascular smooth muscle cells. Am J Physiol Cell Physiol 304:C574-C589

44. Faiyaz-Ul-Haque M, Zaidi SH, Al-Sanna N, Alswaid A, Momenah T, Kaya N, Al-Dayel F, Bouhoaigah I, Saliem M, Tsui LC, Teebi AS (2009) A novel missense and a recurrent mutation in SLC2A10 gene of patients affected with arterial tortuosity syndrome. Atherosclerosis 203:466-471 